\title{
CORRELATION BETWEEN FAMILY CENTERED APPROACH AND MENTAL HEALTH OF PARENTS IN DOMICILIARY THERAPY
}

\section{ABSTRACT}

\section{BACKGROUND AND AIMS}

Parents of children with developmental disabilities were at risk of poor mental health subsequently leads to unfavorable outcome in their children rehabilitation. Therefore, this study aims to rule out the association between family centered approach in domiciliary therapies and mental health in parents of children with developmental disabilities.

\section{METHODOLOGY}

A comparative analysis was conducted to determine the relation between family centered approach in domiciliary therapy sessions and parental stress. The data was collected through self-administered questionnaire, shared during the home visit to participants and mother.

\section{RESULTS}

A total number of 100 home-based therapists included in the study consisted of 79 females (78.8\%) and 21 males (21.3\%). Out of which only $48 \%$ of therapist were using family centered approach where the stress level among parents was low where as $52 \%$ were not inculcating family centered approach due to some constraints and had high level of stress and anxiety among the parents. Moreover, correlation among family centered approach in domiciliary therapy sessions and parental stress is found negatively correlated (i.e. -0.54).

\section{CONCLUSION}

It was concluded that home-based therapists perceived that parents of children with special needs has affected mental health however therapists strive to overcome these challenges by working on family-focused approaches, provide information and do regular meetings to help parents understand their child and found coping mechanisms to adjust with the disability.

\section{KEYWORDS}

Developmental Disability, Mental Health, Child, Parent, Stress, Coping.
Saima Asghar Ali

Occupational Therapist

Sindh Institute of Physical Medicine and Rehabilitation

saimaasgharali@gmail.com
[Ali SA. Correlation Between Family Centered Approach And Mental Health Of Parents In Domiciliary Therapy.Pak.j.rehabil.2021;10(1):7684-]

DOI;10.36283/pjr.zu.10.1/011 


\section{INTRODUCTION}

A number of studies indicated that children with developmental disabilities suffer from long-term physical, mental and social problems that affect their participation in daily living activities, such that in autism, behavioral and intellectual disorders ${ }^{1}$. However, among these disorders, mental disability predominantly varies due to genetic or chromosomal conditions, infections or fetal-alcohol syndrome ${ }^{2}$. These factors may cause the blindness, paralysis, secondary brain injury, learning or behavioral disabilities ${ }^{3}$.

Worldwide, the children with disabilities, particular across Central Europe and Asia are susceptible to stigma and discrimination therefore often segregated in national statistics and become imperceptible to service providers, consequently to the general public while the ratio of children with intellectual disabilities across Asia is estimated to be consistent approximately $1.3 \%$, with exception of $6.68 \%$ in China ${ }^{4}$. Moreover, the data remain scarce on the disable children that are estimated to be 5.1 million across the region, might facing right infringements, leads to paucity of early detection to exclusion from community based participation ${ }^{5}$.

A study conducted by Zechella and Rava (2016) on parenting of the children with developmental disabilities showed a crucial parenting role within a wider socio-cultural framework although it presumed to be affected by gender, ethnicity, societal characteristics ${ }^{6}$. Other features that affects parenting includes cultural contexts to disability, perceived stress due to child's long term care, available social or disability related resources and coping strategies may play a predominant role in parenting interventions ${ }^{7}$. Several studies has shown rising a disable child is emotionally challenging that may optimism versus sadness or no optimism and despair versus desperation. Despite, families of special needs children are constantly experiencing barriers to their fundamental human rights that lead to social inclusion. For that reason, the child abilities are somewhat overlooked underestimated and continue to live with their impairment ${ }^{8}$. In recent era, certain aspects have been changed for these children i.e. gathering of global momentum and increased support by civil society ${ }^{9}$. Moreover, national organizations that have started several campaigns for disable children reforms and appeals to policy-makers to provide fiscal and organizational incentives to sustain the shift in paradigm ${ }^{10}$. Despite, there is a gap that challenges every healthcare professional working with special children and their families. Therefore, with respect to principles of latest paradigm it is important for the practitioners to monitor their own practice and program to reinforce mental state services for alongside increasing mental state demand. In the rural district of Sindh, Pakistan, the incidence of early childhood impairment is common with the estimated prevalence of 5.5 out of 1,000 in children under 2 years of age constitutes $56 \%$ of males with recognized impairment from birth or shortly thereafter $^{11}$ estimated to be 30 out of 1,000 live births for children aged $0-5$ years ${ }^{12}$. Among a variety of developmental disabilities, Cerebral palsy has been described as the most common impairment in developed and underdeveloped countries due to which most of the regions faced many economic and social problems ${ }^{13}$. Moreover, health authorities face a wide variety of urgent needs related to clean water, sanitation, education, and immunization however mental health is relatively low on the priority list. Therefore, mental health needs to be considered much more severe, ensuring the safety and well-being of their children. Besides, psychiatrists 
and therapists may invent a meaningful contribution to this process.

Several studies have shown that parents, in particular mothers, of children with developmental disabilities are more likely to display symptoms of psychological distress and a lower level of well-being than parents of typically developing children ${ }^{14}$. It has been evident caring for a child with special needs may require substantial, extended periods, and energy that increased the everyday burden of their parents ${ }^{15}$. Thus, they are believed to have an elevated risk of high levels of stress, which subsequently leads to depression. Therefore, the mental health needs of adults should be taken into consideration to evaluate for consequences ${ }^{16}$. Several studies indicated that the burden of mental illness on health and productivity is enormous, although specialized medical facilities for people with disabilities are available in some nations; however, the availability of high-quality clinical care remains a key problem ${ }^{17}$. Moreover, there have been few reports on mental health from Asian countries, that services are inadequate to meet the complex mental health needs of people in a manner that is appropriate, sensitive, and effective. Thus, failure to provide services that meet the needs of these individuals may lead to problems such as caregiver stress and inadequate therapy. Moreover, the lack of qualified allied professionals is a major barrier to the growth of this sub-specialty in many countries.

\section{METHODOLOGY}

A cross-sectional survey was conducted at Rehabilitation Department of primary and tertiary care hospitals of Karachi on Occupational and Physical Therapists, providing home-based services to children with developmental disabilities recruited through non-probability, convenience sampling technique.

\section{SAMPLE SELECTION}

\section{Inclusion criteria}

Both male and female therapists providing home-based services to children with developmental disabilities having experience of $\geq 1$ year or more.

\section{Exclusion criteria}

Therapists are dealing with cases other than developmental disabilities with less than a year's experience.

\section{DATA COLLECTION TOOL}

Data was collected through questionnaire which includes four domains of parent's i.e. physical, psychological, social and financial issues comprised of 17 questions on a likert scale of Strongly Disagreement (1) Disagreement (2) Neither the partnership nor the dispute (3) Consent (4) Strong (5).

\section{DATA COLLECTION PROCEDURE}

Due to ongoing Covid-19 pandemic, it was difficult to manually collect the data therefore the questionnaire was formulated in Google Docs and sent to participants social media platforms, Whatsapp group or email. Prior to collection, all participants were given consent form to ensure their voluntary participation. It was ensure that all information of the participants will be kept anonymous under investigator's supervision. After their consent, understanding about the questionnaire was made certain in order to record the responses on the self-administered questionnaire. The data was analyzed upon completion of sample on Google Docs Editor. The demographic characteristics of the participants were represented through frequency, mean and standard deviations whereas the participant responses were evaluated through frequency and percentage. 


\section{RESULTS}

A total number of 100 home-based physical and occupational therapists participated in the survey consisted of 79 females (78.8\%) and 21 males (21.3\%) respectively.

It was revealed that (58.7\%) therapists agreed that they provide guidance and mentoring to facilitate the child-related work in relation to their parents, (12\%) strongly agreed with (17.3\%) remain neutral on this question, rest of them disagreed. Moreover, $(48 \%)$ agreed to the shortage of resources to refer children to healthcare agency according to their disorder. In addition, only (20\%) homebased therapists were agreed to have no desire to meet the family. However, (48\%) were agreed that family-focused practice leads to professional growth and encouragement in the society while $(21.3 \%)$ disagreed to the statement as shown in Figure-1.

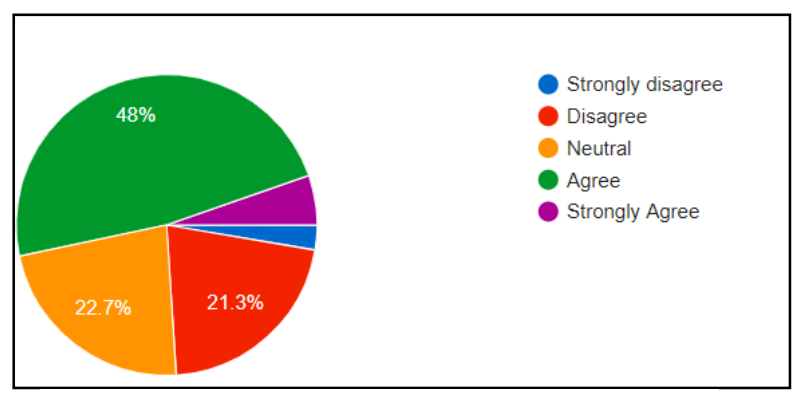

Figure-1 shows family-focused practice by home-based therapists

An over whelming response on receiving help from co-workers for family focused practices was received from $(57.3 \%)$ therapists however (30.7\%) remain neutral to respond. Moreover, (30.7\%) participants reported to have daily meeting with the parents of their patient while (25.5\%) disagreed. Besides, (54.7\%) therapists disagreed to have no faith in working with parents, or on their parenting skills as $(46.7 \%)$ respondents were agreed that number of parents do not show concern for their children with mental disorder while (14.7\%) strongly agreed and $(23 \%)$ remain neutral as shown in Figure-2.

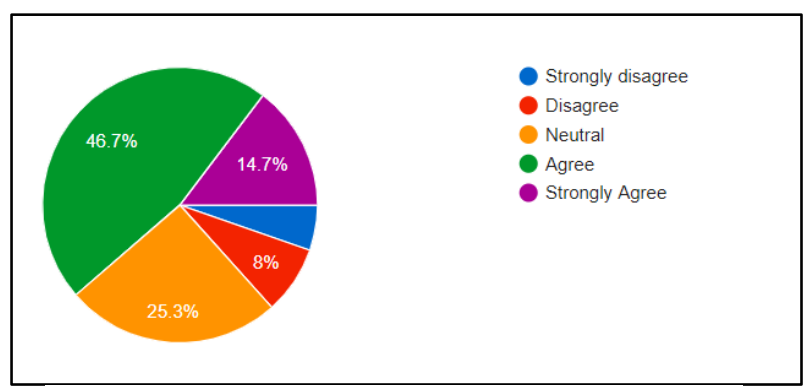

Figure-2 shows concern of parents towards the mental illness of their children

A number of (57.3\%) therapist were agreed to have awareness regarding the effect of parents' mental illness on children whereas $(62.7 \%)$ were agreed to determine the importance that parents placed on their children in activity participation while (20\%) strongly agreed to this statement as shown in Figure-3. However, majority of the participants were unaware of the parental-related programs.

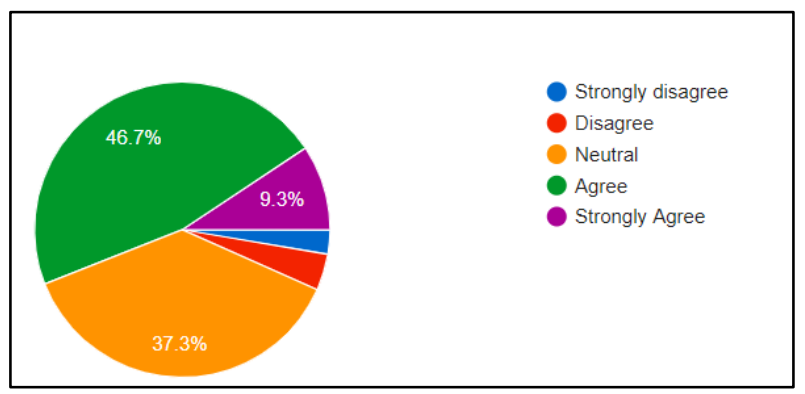

Figure-3 shows percentage of number of constraints faced by home-based therapists in family-focused practice

It was showed that $(46.7 \%)$ therapists provide the parents with the materials such as pamphlets, home program, brochures on parenting and proper child management, and $(17.3 \%)$ strongly agreed while $(26.7 \%)$ remain neutral as shown in Figure-4. Moreover, (65.3\%) were agreed to determine the extent of participation of children in symptoms of their parents, while (9.3\%) agreed to this statement. 


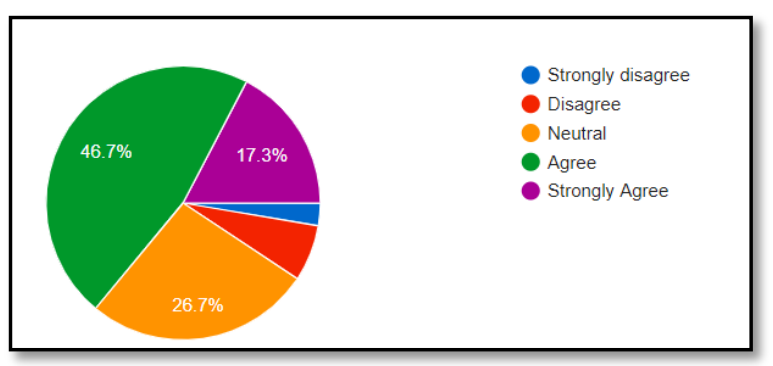

Figure-4 shows percentage of therapists who provided the parents with the materials

A correlation among family centered approach in domiciliary therapy sessions and parental stress is found negatively correlated (i.e. -0.54). Both the variables are significant as the $p$ value is less than 0.05 shown in following table 1 .

\begin{tabular}{|c|c|c|c|}
\hline & & DTS & PS \\
\hline \multirow[t]{3}{*}{ DTS } & Pearson Correlation & 1 & $-.543^{* *}$ \\
\hline & Sig. (2-tailed) & & 0.000 \\
\hline & $\mathrm{N}$ & 100 & 100 \\
\hline \multirow[t]{3}{*}{ PS } & Pearson Correlation & $-.543^{* *}$ & 1 \\
\hline & Sig. (2-tailed) & 0.000 & \\
\hline & $\mathrm{N}$ & 100 & 100 \\
\hline \multicolumn{4}{|c|}{ DTS = Domiciliary Therapy Str } \\
\hline \multicolumn{4}{|c|}{ PS $=$ Parental Stress } \\
\hline
\end{tabular}

\section{DISCUSSION}

The results of this study revealed that majority of therapists have awareness regarding the impact of mental health on parents of children with developmental disabilities. However, varied perception has been indicated in this regard. In addition to it, therapists were observed to deal with certain situations based on their knowledge and skills to reduce the impact of high burden care on the parents. It has been shown from our results that several healthcare professionals practices family-focused approach which help the parents for better understating of their child management, for such approach (58.7\%) therapists agreed that they provide guidance and mentoring to facilitate the child-related work in relation to their parents, however it was also observed that (48\%) parents faced shortage of resources to refer children to healthcare agency according to their condition. Besides, (46.7\%) therapists responded that alliance may be difficult due to number of constraints to connect families and children with the required resources. Despite, it was shown that (46.7\%) therapists provide the parents with pamphlets, home program, brochures on parenting and proper child management to reduce the adverse impact on their mental health. Unfortunately, (48\%) reported that some of the parents do not show concern for their children with special health needs due to burden of care.

Number of studies has predicted that parenting of special children may have long-term concerns for adults associated with greater symptoms of depression, low health-related quality and greater restriction in daily living activities ${ }^{18}$. In addition, the health decline is predominantly observed among these parents over time as indicated in number of studies. This may lead to physical and mental disability thereby required practical concerns and consultation to live health life ${ }^{19}$. Despite to the health decline, a study reported mental health in parents of disable children was negatively correlated with the parenting, in contrast another study predicted that that the long-term parenting of disable child may incrementally worsen the general health of parents over 10 years ${ }^{20}$. However, with the passage of time, these parents also learn essential and new skills in their child management that helps them to adjust with their child's condition.

Besides of these challenges, parents tend to thrive with their child's needs ${ }^{21}$. As current study, home-based therapists seem to have to a certain level of connection with parents of special needs children such that they provide mentoring 
to maintain parent-child relationship, moreover majority of therapists have daily meeting with parents that may also lead to a good understanding of their child's therefore our study suggested that no predominant mental health disorder was found in parents of disable children as they strive for better child's health but indeed mental health is affected to a certain level due to prolonged rehabilitation and care of their child.

Number of studies has been conducted in the past to evaluate the health effects in mother and child showed the greater difference among them ${ }^{22-25}$. Moreover, it was demonstrated that mothers are presumed to be predominantly affected in comparison to fathers due to greater care giving burden ${ }^{23}$. It was also observed that the greater interactions with the healthcare system, leads the primary caregivers vulnerable to depressive symptoms. However, family focused intervention may provide better healthcare outcomes, improves the parent-child relationship subsequently quality of life.

It has been evident that parental role is crucial in a child's life, in association with their psychosocial development. In addition to this, several parenting interventions have been outlined for families of children with neurodevelopmental disabilities for the past few decades ${ }^{20-25}$. These interventions are intended to improve the parental ability to enhance their child's psychosocial well-being through appropriate training, emotional support, and adequate education ${ }^{21}$. However, the use of these programs is less common. Despite the fact, these intervention programs included a variety of training skills that rely on parent's education, coaching, and social support ${ }^{22}$. However, provision of knowledge and parentmediated interventions are observed to be less implemented in child's management. Studies have indicated that these programs are beneficial for the parents to overcome the hurdles faced with their children, specifically with disabilities to manage the developmental, behavioral, and emotional challenges ${ }^{23,24}$. These programs are intended to engage the parents in a small group or individual coaching sessions, seminars. Another mode of delivery includes self-directed, face-to-face, and online-parenting programs ${ }^{24}$. Unfortunately, some studies revealed that the effectiveness of these interventions is not entirely reliant on the utilization of these delivery methods but rather on the incorporated exercises $^{24}$. However, parents may experience some physiological stressors, including stress, anxiety, and fatigue in implementing these programs due to some factors subjected to negative emotional arousal, informal beliefs, or lack of knowledge, etc ${ }^{22}$.

Several studies showed that parents often perceived a high level of psychological stress due to the high burden of management of children with disabilities. It may include several factors that are associated with low confidence in managing disable child, seeking less social support that may be comprised of family, friends, or religious groups' leads to reduce parental-efficacy ${ }^{18-23}$. Similar studies have shown that reduce selfefficacy in a child's management, ended up stressing the entire family itself. Besides, several studies have shown that the role of family adaption is crucial in children with developmental disabilities which may include marital compromises, relationship with a sibling, and concerns for the family ${ }^{22,25}$. On the contrary, it has also been observed that mothers are the ones who played a substantial role in their children's lives, however, fathers tend to play a minor character in comparison that may also a cause for the distress and affects the mental health ${ }^{22,23}$. As each of the children displayed atypical behavior 
related to their developmental disability therefore role of both the parents in their life is of great importance for their wellbeing ${ }^{23}$.

To the best of author's knowledge, this study is the first to be conducted in Pakistan to explore the perception of home-based therapists on mental health in parents of special needs as they spend substantial time with them during their children rehabilitation. There are several limitations faced in the study such as the limited sample size, as during pandemic the home-based therapists were difficult to approach, despite male respondents were comparatively less than females. Moreover, the mental health of parents was assessed by the therapists perception therefore direct examination of the mental health was lacking. However, selfadministered questionnaire lacks relevant questions of mental health and burden of caregiver.

The findings of this study can be informative for future researches to be conducted by clinicians and educators with families of special children. Future researches must include longitudinal designs with refined measures to evaluate the health-related outcome.

\section{CONCLUSION}

It was concluded that home-based therapists perceived that parents of children with special needs has affected mental health however therapists strive to overcome these challenges by working on family-focused approaches, provide information and do regular meetings to help parents understand their child and found coping mechanisms to adjust with the disability.

\section{REFERENCES}

[1] Boyle CA, Boulet S, Schieve LA, Cohen RA, Blumberg SJ, Yeargin-Allsopp $M$, Visser $S$, Kogan MD. Trends in the prevalence of developmental disabilities in US children, 19972008. Pediatrics. 2011 Jun 1;127(6):1034-42.

[2] Christensen DL, Braun KV, Baio J, Bilder D, Charles J, Constantino JN, Daniels J, Durkin MS, Fitzgerald RT, Kurzius-Spencer $M$, Lee LC. Prevalence and characteristics of autism spectrum disorder among children aged 8 years-autism and developmental disabilities monitoring network, 11 sites, United States, 2012. MMWR Surveillance Summaries. 2018 Nov 16;65(13):1.

[3] Cohrs AC, Leslie DL. Depression in parents of children diagnosed with autism spectrum disorder: A claimsbased analysis. Journal of Autism and Developmental Disorders. 2017 May 1;47(5):1416-22.

[4] Dunkley-Smith AJ, Sheen JA, Ling $M$, Reupert AE. A Scoping Review of Selfcompassion in Qualitative Studies About Children's Experiences of Parental Mental Illness. Mindfulness. 2020 Nov 26:1-6.

[5] Hsiao YJ. Parental stress in families of children with disabilities. Intervention in school and clinic. 2018 Mar;53(4):201-5.

[6] Ibrahim, S.H. and Bhutta, Z.A., 2013. Prevalence of early childhood disability in a rural district of $S$ ind, $P$ akistan. Developmental Medicine \& Child Neurology, 55(4), pp.357-363.

[7] Opitz JM. American journal of medical genetics. Part C, Seminars in medical genetics.

[8] Zwicker JG, Suto $M$, Harris SR, Vlasakova $\mathrm{N}$, Missiuna C. Developmental coordination disorder is more than a motor problem: Children describe the impact of daily struggles on their quality of life. 
British journal of occupational therapy. 2018 Feb;81(2):65-73.

[9] Parenting $\mathrm{Cp}$. Core Principles and Techniques Of Positive Parenting. The Power of Positive Parenting: Transforming the Lives of Children, Parents, and Communities Using the Triple P System. 2017 Nov 20:63.

[10] McGuire DO, Tian LH, Yeargin-Allsopp $M$, Dowling NF, Christensen DL. Prevalence of cerebral palsy, intellectual disability, hearing loss, and blindness, National Health Interview Survey, 2009-2016. Disability and health journal. $2019 \mathrm{Jul}$ 1;12(3):443-51.

[11] Namkung EH, Greenberg JS, Mailick $\mathrm{MR}$, Floyd FJ. Lifelong parenting of adults with developmental disabilities: Growth trends over 20 years in midlife and later life. American journal on intellectual and developmental disabilities. 2018 May 1;123(3):228-40.

[12] Hughes RB, Robinson-Whelen $S$, Raymaker $D$, Lund EM, Oschwald $M$, Katz M, Starr A, Ashkenazy E, Powers LE, Nicolaidis C, Larson D. The relation of abuse to physical and psychological health in adults with developmental disabilities. Disability and health journal. 2019 Apr 1;12(2):227-34.

[13] Lee MY, Lee TY, Lee YC. Experiences of Family Resource Utilization Among Taiwanese Parents of Children with Developmental Delay. Journal of pediatric nursing. $2020 \mathrm{Jul}$ 1;53:e20410.

[14] Olusanya BO, Davis AC, Wertlieb D, Boo NY, Nair MK, Halpern R, Kuper H, Breinbauer C, De Vries PJ, Gladstone $M$, Halfon N. Developmental disabilities among children younger than 5 years in 195 countries and territories, 1990-2016: a systematic analysis for the Global Burden of Disease Study 2016. The Lancet Global Health. 2018 Oct 1;6(10):e1100-21.
[15] Osmančević Katkić L, Lang Morović $M$, Kovačić E. Parenting stress and a sense of competence in mothers of children with and without developmental disabilities. Hrvatska revija za rehabilitacijska istraživanja. 2017;53(Supplement):63-76.

[16] Lawrence PJ, Rooke SM, Creswell C. Prevention of anxiety among at-risk children and adolescents-a systematic review and meta-analysis. Child and adolescent mental health. 2017 Sep;22(3):118-30.

[17] Robinson S, Hastings RP, Weiss JA, Pagavathsing J, Lunsky $Y$. Selfcompassion and psychological distress in parents of young people and adults with intellectual and developmental disabilities. Journal of Applied Research in Intellectual Disabilities. 2018 May;31(3):454-8.

[18] Scherer N, Verhey I, Kuper $H$. Depression and anxiety in parents of children with intellectual and developmental disabilities: A systematic review and meta-analysis. PloS one. 2019 Jul 30;14(7):e0219888.

[19] Neece CL, Chan N. The stress of parenting children with developmental disabilities in Parental stress and early child development 2017 (pp. 107-124). Springer, Cham.

[20] Woodman AC, Hauser-Cram P. The role of coping strategies in predicting change in parenting efficacy and depressive symptoms among mothers of adolescents with developmental disabilities. Journal of Intellectual Disability Research. 2013 Jun;57(6):513-30.

[21] Zechella AN, Raval VV. Parenting children with intellectual and developmental disabilities in Asian Indian families in the United States. Journal of Child and Family Studies. 2016 Apr 1;25(4):1295-309.

[22] Marsack CN, Samuel PS. Mediating effects of social support on quality of life for parents of adults with autism. 
Journal of Autism and Developmental Disorders. 2017 Aug;47(8):2378-89.

[23] Cappe É, Poirier N, Sankey C, Belzil A, Dionne C. Quality of life of French Canadian parents raising a child with autism spectrum disorder and effects of psychosocial factors. Quality of Life Research. 2018 Apr;27(4):955-67.

[24] Cappe E, Bolduc $M$, Rougé $M C$, Saiag MC, Delorme R. Quality of life, psychological characteristics, and adjustment in parents of children with attention-deficit/hyperactivity disorder. Quality of Life Research. 2017 May 1;26(5):1283-94.

[25] Scherer N, Verhey I, Kuper H. Depression and anxiety in parents of children with intellectual and developmental disabilities: A systematic review and meta-analysis. PloS one. 2019 Jul 30;14(7):e0219888. 